\title{
Journey of School Principals in Coping the Demands and Challenges of School Development
}

\author{
Maylene D. Morales', Sherwin B. Sapin ${ }^{2, *}$ \\ ${ }^{1}$ Butong Elementary School, City Schools Division of Cabuyao, Department of Education, Philippines \\ ${ }^{2}$ Graduate Studies and Applied Research, Laguna State Polytechnic University, Philippines
}

Received June 17, 2020; Revised August 26, 2020; Accepted September 29, 2020

\section{Cite This Paper in the following Citation Styles}

(a): [1] Maylene D. Morales, Sherwin B. Sapin , "Journey of School Principals in Coping the Demands and Challenges of School Development," Universal Journal of Educational Research, Vol. 8, No. 11B, pp. 6297 - 6306, 2020. DOI: 10.13189/ujer.2020.082269.

(b): Maylene D. Morales, Sherwin B. Sapin (2020). Journey of School Principals in Coping the Demands and Challenges of School Development. Universal Journal of Educational Research, 8(11B), 6297 - 6306. DOI: 10.13189/ujer.2020.082269

Copyright $\subseteq 2020$ by authors, all rights reserved. Authors agree that this article remains permanently open access under the terms of the Creative Commons Attribution License 4.0 International License

\begin{abstract}
This transcendental phenomenological study focused on analyzing and scrutinizing the lived experiences of school principals in the City Schools Division of Cabuyao. This study is geared towards achieving the central question of determining the journey of school principals in coping with the demands and challenges they encountered for school development. The researchers deemed that conduct of Key Informant Interview was suitable for attaining the problem's statement. Since the research problem of this inquiry focused on describing and understanding the lived experience of public school principals, which is a phenomenon in academia, the researchers used phenomenological research design. The study reflected the challenges and demands encountered by the school heads as well as the strategies and techniques they utilized to surpass them all. This study also provided an illumination that the school heads need to extend the horizon and tried their best to attain the acme of school success.
\end{abstract}

Keywords Phenomenological, Lived-experiences, School Heads, School Development

\section{Introduction}

The worth of any educational system as an investment lies in its capability to continuously serve its customers, students, parents, and the society better and remain relevant. The desire for better quality of education is a generally shared feeling in many other countries. The traditional practices of quality control through school inspection, auditing and monitoring are mere retroactive actions taken after possible damage had been done.

For so many years, educational leaders have been seeking ways to discover the best educational experience for school children - the perfect place that would provide children with the best possible educational experiences, enable them to realize their potentials and make them prepared to meet global challenges.

Each school needs a principal who shall manage and supervise teachers for the delivery of quality education and carry out educational programs, projects, and services. The said principal is accountable and responsible for administering the over-all school operations. In this manner, the principal must portray excellence in leadership in striving the success of managing school to carry out the duties and responsibilities as stated in Republic Act No. 9155.

School heads as the forerunners of schools also deal with various problems concerning the various aspects of school leadership. The new trend of the learning arena, the composition of the teaching force, the challenges of management and administration have been considered as major problems among school heads.

Changes in expectations by the education system and the parent community, coupled with rapid changes in the 
technology and society itself, have added to the demands of the role without necessarily taking away any of the pressures which principals face on a day to day basis. As the role of the principal has become more challenging and multifaceted, the effects of the role in their well- being are becoming the focus of research efforts. It behoves schools, education system and government to consider the effects of work related factors on their principals as a matter of duty of care and as a genuine commitment to work towards their well-being and career longevity. In the work of [1], school leaders nowadays face the challenges of forerunning the school in making it relevant to the needs of learners and the community. However, challenge is usually related to the ability of the school versus the demands of the society. People could not easily understand the challenges faced by the school leaders. Most of them observed the physical situations of the school and usually ignored the internal operations undertaken by the school leaders just to be able to serve the school and the community.

School heads have also been prepared to face the ever changing society where the views of people towards school heads have also been changed. The school heads in these generations have been in challenge of making the school child -friendly and where the spirit of transparency shall be felt and observed. Further, the demands among school heads have also been dramatically changed due to the implementation of various programs and projects related to the improvement of the education system and in making the school as better training ground for the future leaders of the nation.

In the recent study conducted by [2], opportunities to lead the school is one of the major goals of educators who may look after the school and exert effort to cater quality education that may also be contributory to the development of the education system. School heads have also been prepared to face the ever - changing society where the views of people towards school heads have also been changed.

Moreover, as articulated in Department of Education (DepEd) Order No. 32 s. 2010, the National Competency Based Standards for School Heads (NCBS-SH), school heads shall be competent, committed and accountable in providing access to quality education for all through transformational leadership and high degree of professionalism.

Finally, the researchers arrived at this study to gain knowledge and understand the lived - experiences of school principals, to encourage and motivate aspiring principals to pursue their dream as future school leaders and to strengthen the management and administrative skills of principals in the years to come.

\section{Objectives of the Study}

This study focused on analyzing and scrutinizing the journey of school principals. This study also determined the essence of the lived- experiences of school principals in dealing with the demands and in coping challenges they encountered as heads of the school.

\section{Materials and Methods}

\section{Research Design}

This study is of Qualitative Type of Research, a design which is used to deeply scrutinize the essence, nature and rudiments of the problem. It focused on in-depth studies of small groups of people to guide and support the construction of hypotheses. The results of qualitative research are descriptive rather than predictive. Qualitative research methods originated in the social and behavioral sciences: sociology, anthropology and psychology [3]. Qualitative research methods originated in the social and behavioral sciences: sociology, anthropology and psychology. Today, qualitative methods in the field of marketing research include in-depth interviews with individuals, group discussions (from two to ten participants is typical); diary and journal exercises; and in-context observations.

Among the various methods of the Qualitative Transcendental phenomenological study, the researchers deemed that conduct of Key Informant Interview is suitable to attain the statement of the problem. Since the research problem of this inquiry focused on describing and understanding the lived experience of public school principals which is a phenomenon in the world of the academia, the researchers used phenomenological research design.

This paper was specifically structured with psychological phenomenology, largely developed by [4], which is a philosophical approach to qualitative research methodology seeking to understand human experience [3]. Psychological phenomenology, also termed as transcendental and empirical, is grounded in the concept and conditioned upon setting aside all preconceived ideas (epoche) to see phenomena through unclouded glasses, thereby allowing the true meaning of phenomena to naturally emerge with and within their own identity [3].

\section{Population and Sample}

Primary data were collected through Key Informant Interview with 10 school principals in the City of Cabuyao, province of Laguna who have been school principals for 5 years and beyond. According to [3], the researchers need to interview 5 to 25 individuals who have experienced a particular phenomenon in order to collect enough data to understand the rich detail of the essence of the experience. Secondary sources of data culled from books, journals, and germane articles from the Internet. 
The purposively sampled participants provided an understanding of the research problem and central phenomenon in the study; thus providing quality assurance [3]. The participants engaged in an open and honest discussion. Given the nature of qualitative research, pseudonyms were assigned to all public schools and public school principal participants to ensure and maintain privacy and confidentiality.

\section{Research Instrument}

According to [3], the major components of research questions are the "how" and the "what" that lead to a described experience because these questions lead to openness. To address this study, thorough, purposeful, and well-conceptualized qualitative research questions were formulated. The researchers used these guides in conducting the Key Informant Interview. Thus, in this research, the researchers were the primary instrument and her guide was the interview protocol.

This study used one central question to help describe the true essence of the experience this is "What is the essence of the lived experience of school principals in dealing with the demands and challenges they encountered as head of the school?” The questions functioned together to discover the true meaning of the experienced phenomenon. From the central question, an Interview Guide Questions (IGQ) were developed and used in conducting interviews.

This guide was self-made and semi-structured so flexibility in asking questions during the interviews with the participants was ensured. Long and Key Informant Interview is important to describe the meaning of a phenomenon for a small number of individuals who have experienced it as cited by [3]. Through the interview guide, the researchers were able to take notes of the responses of the participants and organize thoughts on items such as headings, information about starting the interview, concluding ideas, information on ending the interview, and expressing her gratitude to the participants.

\section{Ethical Considerations}

The ethical guidelines as specified in the Research Manual of the school were followed by the researchers. The researchers strictly considered formal stages of communication for ethical consideration throughout this paper.

For this study, it intended to look into the livedexperiences of school principals, no questions can cast insult on the capabilities of the principals included in the sub-questions. In addition, the sub-questions were constructed in such a way that there was no discrimination or any reference to specific religion and organizations. Also, the researchers did not specify the school, where the participants served as school principals. The researchers obtained the permission of the participants regarding the audio-visual recorded interview for the verbatim transcriptions of their accounts. Finally, the researchers verified and assured that the transcribed interviews were all based on the participants' responses. No omission, no alteration nor additional words or phrases were included in their answers to ensure the validity and reliability of the study.

\section{Results and Discussion}

This research is guided by the following central question: What is the essence of the lived experiences of school principals in dealing with the demands and challenges they encountered as head of the school? Corollary Question Number 1: How do the school principals deal with the demands and the challenges they encounter as head of the school? The horizonalization of the study was presented through listing significant statements that were extracted from the verbatim transcription of the participants' responses. These statements were read and analyzed many times to answer the two central questions with probing questions in research interview protocol. As a result, the researchers were able to come-up with thirty-three (33) significant statements, which were extracted from the conversations with the participants.

In theme clustering, the researchers classified 10 themes for textural descriptions and structural descriptions.

Theme 1: Passion and Dedication bridge the dream into reality. School principals shoulder the biggest roles and responsibilities on their respective school. They are the forerunners of school who shall take the biggest functions to be able to attain the vision and mission of the school and the entire Department of Education. Further, the school principals also play vital roles through which the overall success of the school depends on their ability to lead and supervise the school. Thence, there is a need for the school principal to be vested with the passion and dedication towards their vocation to abreast with other individuals who shall march forward to cater quality among learners and to produce quality learners and productive citizens.

Most of the school heads involved in this study believed that their passion and dedication have bridged their dreams into reality. They are really motivated to serve the school to be able to cater to quality education. These are well-manifested to the following responses: Stated below are the annotated exemplar for this query:

Principal B. My main motivation to achieve my current position is my passion and advocacy that $I$ can be a catalyst of change especially in achieving quality basic education and in producing functionally-literate learners. My drive that, I will contribute to uplift the current status of our educational system.

Principal C. And this motivated me to be in my current position for I know that there is always a reason for everything. How to have a school with high performance 
motivates me to do my duties and responsibilities as a good school head.

Principal F. It's a call of duty for a school principal like me who wanted to make change for the good of our youth, it's enough for them to be motivated to stay in the position.

Principal G. My dedication and perseverance to be an instructional leader.

Principal $J$. It was indeed my passion and dedication to contribute to the improvement of the system that motivated me to serve as a school leader. I really wanted to make a change, to start a change in the system that I have witnessed need to be ameliorated and improved.

Principal I. Modesty aside, but I really eager to make a change in the system through my passion and dedication in this vocation. I am motivated to do hard and lead the school the way I think would help each learner to become successful in life.

According to [5], it is more the school leader's dedication which enabled him to run the school more effectively. Moreover, he also suggested that this dedication of the school shall also enthuse the teachers and other school personnel to exert their time, efforts, and dedication which may help the school as a whole attain its main goal of catering quality education.

Theme 2: Being school head as calling and fruit of hard work. School heads as the leaders of the schools have been perceived as individuals who shall take parts of leading the school towards success- through quality education. They also shoulder broad and heavy duties and responsibilities of taking actions that will benefit everyone in school particularly the learners.

In this particular portion, the school heads were asked "Did you really imagine that you are at your position right now?” Listed below are the annotated exemplar taken from the responses of the school heads:

Principal B.I realized that God Almighty prepared me for what I am right now. Indeed, it is a calling. As a teacher, I exposed a lot to managerial and supervisory tasks, a very challenging one but I didn't refuse those difficult challenges assigned to me without any complaints and hesitations. I considered it as new learning opportunities, that later on, I benefited from it.

Principal $D$. No, that's the only dream for me.

Principal E. I always dream that someday I will become a school head.

Principal F. It came to my life unexpectedly without imagining to be there but once it happens, you will imagine your next position since it becomes part of your plan.

Principal H. I work hard to achieve this position. It was a dream come true.

Principal I. It was indeed like a spark. I could believe that I finally get the position I have been dreaming of. But I also believe that it is more of God's calling. I know that he placed me in this position that I deserve out of my hard work and perseverance.

Principal J. It was my dream and the very reason why I have poured all my effort. I really wanted to manage a school.

Each school head as his/her experiences before getting the position. There are principals who never expect that they would be in their place now. While others have been motivated to work hard and do all their best to be able to attain their dream to become the head of a school.

Theme 3: Leaping from a position has brought various changes. Everyone works hard to sustain their needs and to provide the needs of the people they love. Educators, regardless of their difficult callings actually have the fortitude and are spurred to outperform the difficulties and challenges they generally experience. Out of their perseverance and hard work, teachers were promoted to higher level of teachers. Others, who have the dream of leading and managing the school took the NQESH, and fortunately passed the exam which served as their tickets to forerun the school. Having been promoted from being teachers into school heads also brought them a lot of changes, particularly their roles and functions as well as the goals and objectives. The focus of ensuring the quality of instruction to their learners has changed into ensuring the quality of education the school cater among the learners of the school. Further, they also opt to ensure that the school is well-managed, supervised and lead.

These realities are shown in the responses of the school heads as explicated below:

Principal B. It's really a big transformation for me, from just a simple classroom teacher, whose aim was just to improve the academic performance of my pupils to a school head, leading and managing the entire school. Another chapter of my life as a teacher ended for 18 years to give way to fulfill my ultimate prayer to become a principal.

Principal C. My position as a school principal really change my life 360 degree from a simple and motivated teacher where my focus was only for my pupils until I became a school principal wherein the school is in my full responsibilities and accountability. Where supervisory and administrative functions must be performed by me, where I must be acquainted with all the personnel in the organization and be knowledgeable on how stakeholders in me as the head of the school.

Principal D. There were lots of changes, I have to take care of my actions towards issues. I need to balance everything in my workplace most especially to teachers' concerns.

Principal E. There was a big change for me. Before I'm teaching lessons to my students now, I'm managing the school.

Principal J. Before I'm just concern on how to manage my class. But now the focus is on the whole school and really enormous when it comes to management. 
Principal G. Before. my focus was only for the best performance of the learners, but this time, complex direction focuses on learners' performance, school achievement, rewards and recognition of teachers, students and stakeholders.

Principal $H$. I can say that being a school principal has fully changed my professional facet. My functions as an educator have changed from just simply ensuring quality teaching among my learners into a bigger responsibility of ensuring that everything in school goes well.

The responses of the school heads have made a clear view of the changes among them as educators. Their simple vocation of catering quality education has changed into a broader scope of works, roles, functions, and responsibilities. It can also be noticed from their responses that they admit the fact that they are the central persons of all the transactions in school, that since they are the highest persons in authority they need to duplicate themselves for the benefits of the entire school.

In the study conducted by [6], the first three years of change in the profession of school principal who is a former teacher is indeed very challenging. The neophyte school principals have to prepare in facing the challenging since they are the highest persons in authority in their respective schools.

Theme 4: Diversity as a big problem for the principals. As the highest authority in the school, it calls the school heads to ensure the effective transfer of learning from the higher office down and will greatly benefit the learners. However, along the way, principals who are installed into their respective schools meet different people; of different races, with different outlooks; and culture. Further, schools also differ in their situation- particularly the school overall environment. The responses of the following principals show that teachers' diversity has been perceived as one of the challenges of being school principal which are manifested to the following statement:

Principal B. There are many challenges I encountered as a school head but the most challenging one is dealing with the behavior of teachers. Keeping them as one - in working and achieving one common goal. Diversity and culture should be considered in leading people. Through this, it enlightens me on the importance of accepting their individual differences.

Principal C. I encountered many challenges, some of them are how to gain the trust of stakeholders to support the school, how to make the school perform better than before, how to be familiarized with the attitude, characteristics and needs of all the school personnel, how to maintain a child-friendly environment in the school.

Principal F. Different behaviors of teachers, parents, and stakeholders towards change affect the system in achieving goals.

Principal I. Indeed, the diversity of the people in the school is considered as the most challenging part of being the head. I really find it hard to consider the needs and demands of each teacher, parents, and the stakeholders. However, I still find ways on how to make a decision which will be benefited by the majority and for the whole sake of the school.

Normal scenario in every school is greatly manifested in the responses of the school heads. The diversity of the school's culture, the people and the environment has enabled the school leader to face a variety of demands and challenges they face. However, it can also be noticed from the responses of the school heads that despite of this diversity, they all wanted to lead the school in attaining quality education through effective instructional supervision.

Theme 5: Good and open communication as formula to solve the challenges. School as an educational institution composed of professional teacher who shall have the ability to understand each one and partake actions in attaining the goals of school in nestling the learners and provide them quality education. However, it cannot be denied that there are times that teachers may not perceive things affirmatively. This creates challenges and problems among the teachers themselves, and even with the school principals.

The principals believe that the best formula to solve the problem is to open the issue and to create an open communication with the concerned individuals. However, it is also divulged on their responses that the main focus of the communication is to solve the issue and to make a closure and move on with the regular school operations. Hence, it is necessary for the school heads to lead school trough open communication to help solve the identified problems.

These are all shown in the following responses:

Principal A. To teachers, I'll talk to them personally, heart to heart and made them at ease during our conversation. Open communication is all what I have to tell them. I let them feel that I am always here for them.

Principal B. Leadership with the intension of serving the people right, fair and just was observed to attain equality and value that they are all important players in an organization. Breaking a culture whether good or bad really takes time and effort to mould them to become precious gold.

Discussing DepEd orders, memo, civil service rules and regulations and code of ethics for professional teachers also helped me a lot in resolving those issues. Through these, teachers are now aware of their actions and responsibilities.

Principal F. Always think of intense study, thorough analysis of the situation and set positive expectations from the teachers, parents and other stakeholders to have open communication among others, active participation in majority of the projects and activities and commitment to learners and school. These challenges may hinder my concentration and focus toward my stand by making my 
plan a little bit delay in terms of implementation because further analysis may be required to overcome such challenges but it does not mean to halt.

Principal H. Proper approaches and good communication, playing as good listeners.

Principal I. I still uphold and believe in the saliency of open communication. It is still the most powerful tool to solve the problem between individuals. As a school head, I give the teachers a chance to speak out their side and from then, I would be able to construct the decision which I think would be helpful enough for the concerned individuals and may not affect the overall school operation.

As divulged in the responses of the school administrators, one way of dealing with the ever changing needs and demands of the school and the society is through a meeting. It is a form of communication wherein a specific concern related to instructional supervision can be addressed.

According to Elago [7], the school personnel shall have an effective mechanism of how to discuss school significant matter which shall be properly discussed to be able to arrive with an effective solution. Further, it may also help the school administrator to strengthen their ability to look into the things that they have not observed. It may also give them sufficient ideas on underpinning their functions as the supervisors of instructions and to meet the expectations and demands of the teachers, learners, parents and the community.

Theme 6: Shared Governance as Strategies in Surpassing the Challenges. School heads handle the highest and multifaceted position that shall deal with the numerous transactions and operations of the school. Aside from these very board roles and responsibilities, the very core of their profession is the leadership and governance of school. Another is the eclectic role which encompasses everything about instructions in school. This role of the school head is commonly perceived as one of the toughest since it calls a lot of patience from the school heads themselves and mostly in dealing with the teachers.

This ability is reflected in the statements of the following school heads:

Principal C. Some of the strategies I use to address for their problems are having orientation with the school personnel, knowing them by having closed supervisory functions. Meeting/Orientation with the stakeholders to make them oriented with different policies. Recognizing the support given by the stakeholders. Providing leaflets every SOSA to let them know what is the accomplishment of the school. Having TEA Governance Bulletin Board for everyone to be informed about financial updates of school. Office of the principal is always open for suggestions and queries.

Principal I. I always believe the significance of Shared Governance, that it is needed in my profession to seek ideas and support to the internal and stakeholders of the school. It is a way to hear what they say and to partake actions to the most significant undertakings of the school-specifically, when it comes to decision making.

Principal E. Involving teachers in making action plans to address such problems in school.

Principal F. Presenting plans, calling for a meeting and focused group discussion are usually done in dealing with such challenges with the teachers, parents, and stakeholders. Discussing with the internal and external stakeholders about the plans for programs, projects and activities during meetings and let them realize that every great thing that may happen always takes time to achieve. Appropriate approach and studying one's behavior/character, principles and condition are also considered.

Principal G. Some of the techniques are positive attitude towards the problems, establish planning mechanism, involving stakeholders in different programs and give recognition and merits to the partners involved.

Principal J. One of the most effective strategy is to apply the essence of Shared governance. This gives an opportunity for the school heads to work hand-in-hand with both internal and external stakeholders in solving the problems of the school.

It is well-manifested on the responses of the school heads that the major stratagem towards effective management and leadership of school is to apply the system of shared governance to build strong relationship and partnership with the teachers, parents, and the stakeholders and to seek their help in solving the big problem of the school. They might hold the highest position in their respective schools but one thing for sure, they also have normal body parts which cannot do all these tasks alone.

Theme 7: Human behavior and attitude as striking problems among school principals. Principal as the head of the school is expected to perform the most significant roles to ensure the delivery of the quality instruction. He or she shall also take the challenge to ensure that everything in school goes well. Further, the school principal is a multifaceted professional where he/she dominantly is expected to deal with people. The hardest part indeed is to hearten the teachers, to abreast with them and to make them dedicated to providing quality education which shall benefit the learners and the community in the large plane.

These realities are reflected on the listed annotated exemplar from the responses of the respondents:

Principal A. Some teachers do not like to attend live-in seminars and they tend to excuse themselves from extra work or assignment during weekends. Teachers like to change their subject coordinatorship even though they are most familiar with it.

Principal C. School heads must be visionary, with wide perspective and know how to get well with all the stakeholders. Also, there are times that I found hard to 
deal with the demands of teachers. Honestly, they gave me challenges in terms of Human Resource and extent of leniency.

Principal D. Decision making for every conflict situation. I also encountered problems of dealing with the behavior and attitude of teachers.

The responses of the school heads simply showed the demands they faced as leaders of the school. Generally, as reflected in the responses of the participants, the demands were on the part of the teachers whose behaviors have challenged the school heads. It can also be noted from the responses that teachers have the courage to speak out their minds. It also shows that they are too careless of giving out their perceptions to the task given by their immediate supervisor. The result is similar to the findings of [8] that the school principals nowadays are not just challenged by the programs, projects, and demands of DepEd but also they are challenged with the best strategies on how to encourage the teachers to have the passion and dedication towards teaching. There are principals also who have difficulty in dealing with the attitude and behavior of teachers who usually decline the tasks assigned to them.

Teachers are diverse in many ways and these have created one of the biggest problems in the part of the school heads. They need to look into the best way on how to think and do things which will be accepted by all teachers in spite of their differences. Further, it cannot also be denied that one of the major problems that the school heads are facing nowadays is the ever changing attitudes and behavior of teachers. There are these teachers who tend to defend their own beliefs even if they violate the rules implemented in the school and in the department. This somewhat creates a divergence between the school head and the teachers. Indeed, these are uncontrollable aspects.

Theme 8: Open-System of Communication lenses strategic mechanism. A wide-range responsibility of the school head is the leadership that covers almost everything related to teaching- and learning and where effectiveness is reflected to the school overall performance. As huge responsibilities, the principals are expected to face a variety of demands and challenges that test their capabilities of how to spearhead their respective schools. School performance and the learning outcomes mirror their effectiveness as the head of the school and also lenses their ability to find a strategic mechanism of facing all these demands and challenges.

These ideas are also reflected to the responses of the participants below:

Principal A. Open communication to all which is supported with memos wherein their names are indicated. For health reasons as the cause they are required to show their medical certificate. For absences, these are charged to their service credits or pay deduction. Conducting parents' assembly and general PTA meetings.

Principal C: A democratic way of leading the organization by asking the opinion of others.

Principal F. I must always think positive and prove that everything can be achieved through proper planning and collaboration of the school and its benevolent partners.

Principal H. I cannot do all these things alone. I usually asked help from people who might have ideas, knowledge, and skills, on the problems and challenges I face. I also seek participation and collaboration of everyone in school who may help me up to solve the problems immediately. Collaborating with people around me is one of the most vital strategies that help me face the challenges and demands as school heads.

Principal J. I usually try my best to reach the concerned individuals to discuss the matter. I often conduct conference with the parents, teachers, and other school personnel and set a well-established form of communication which may be of big help to solve the problems.

This strategy gives equal opportunities for the teachers and the stakeholders to speak out their minds on the things they think would be worthy to solve the problems faced not just by the school head but the entire school. An open-system of communication also provides an avenue for the school heads and their subordinates to meet their ideas and be abreast towards the most possible solution to the identified problems. An open communication is an effective tool to attain the goal of an organization. In the school setting, the school leader shall have the ability to establish an open communication as a mechanism in solving the most frequent problems in school.

Theme 9: Calmness towards oneness and success. School as an organization is a niche of professionals in which sometimes, each of these professionals might have different views and ideas. It is one of the major responsibilities of the school principal to find ways on how to make a decision that would be fair and just for everyone. Additionally, the principal shall also partake the huge roles of making the school a niche for professionals with sense of responsibilities and with one common goal for school success. The participants in this study have common answers that being calm and relax might bring a positive impact to solve the challenges they face. These are all manifested on the following statements:

Principal D. A democratic way of leading the organization by asking the opinion of others.

Principal F. Keeping myself calm, working with my strategies and consulting the top management. See to it that all programs, projects and activities are properly implemented by means of capacitating teachers to ensure that they are well-equipped in providing basic quality education to the learners.

Principal I. I keep myself calm for which I think would give me a moment to find the best solution to the problem and demands. I never show sweep anger which I think would affect my professional facet. 
Principal J. I tend to keep quiet, pause for a while and think deeper.

Then, in a very calm manner I prefer to keep calm and think of things which I think would be the most appropriate answer to the problem.

School heads in spite of the roles and responsibilities bestowed upon them by the department of education shall have the courage to face the challenges and execute ways on how to deal with these problems that may not affect anyone in the school and where everyone in school may take benefits. They are also expected to act professionals even if they face the huge challenge on their professional facets.

Theme 10: Collaboration Outshines Challenges and Demands. It would be a hefty challenge for the school head to stand alone and face the problems of the school, meet the expectations of the school personnel and the stakeholders, and to face the demands of the society. The school heads also carry the heaviest loads as the leader of the school. They also handle the key towards success as to turn it to the left and right until to open the opportunity to improve the overall performance of the school.

The participants in this study have common answers that being calm and relax might bring a positive impact to solve the challenges they face. These are all manifested on the following statements:

Principal D. A democratic way of leading the organization by asking the opinion of others.

Principal F. Keeping myself calm, working with my strategies and consulting the top management. See to it that all programs, projects and activities are properly implemented by means of capacitating teachers to ensure that they are well-equipped in providing basic quality education to the learners.

Principal I. I keep myself calm for which I think would give me a moment to find the best solution to the problem and demands. I never show sweep anger which I think would affect my professional facet.

Principal J. I tend to keep quiet, pause for a while and think deeper.

Then, in a very calm manner I prefer to keep calm and think of things which I think would be the most appropriate answer to the problem.

The real essence of the school heads is to help their people be on their sides in all endeavors of the school. They need to extend their hands in letting everyone in school be part of all the undertaking of the school. Further, the school heads shall also lead to building the spirit of collaboration to each and among school personnel. They shall also establish a well-defined organizational goal which needs the supports of everyone both internal and external stakeholders of the school. The center of this collaboration is the learners who may take benefits from this. The better way for school heads to manage their schools is to get feedback through instructional supervision, to make necessary adjustments and make them more effective. As the heads of the school, the principal shall serve as the instructional leaders who shall aim to develop the instructional process that will be able to deal with the challenges and demands on their profession.

School administrators are the persons in authority who take the highest and the biggest responsibilities in their respective schools [3]. Biggest roles of the being the school head are the management and leadership of their respective schools which are greatly related to their ability to the overall pertain of the school and to enable them to cater to the best quality education which shall be fully benefited by the learners. Being the head of the school also encompasses ensuring the implementation of the educational vision and mission of the school and the entire Department of Education through overseeing, equipping and empowering teachers to provide meaningful learning for the all types of learners.

Just like the rest of other professions, the school heads also encounter various challenges and demands related to it. These test their ability to face them all and to execute their knowledge and skills on how to surpass all these challenges and demands. School Leadership and management have become integral components and process in the functioning of the school. Moreover, the school heads shall need to look into ways on how to improve the instruction in school and to ensure better learning outcomes.

The aforementioned fundamental themes for textural descriptions (Theme 1: Passion and Dedication bridge the dream into reality; Theme 2: Being school head as calling and fruit of hard work; Theme 3: Diversity as a big problem for the principals; Theme 4: Shared Governance as Strategies in Surpassing the Challenges; Theme 5: Human behavior and attitude as striking problems among school principals; Theme 6: Calmness towards oneness and success.

As how the participant faced the challenges and demands as school heads, the significant statement resulted to four themes for structural descriptions: Theme 1: Leaping from a position has brought various changes; Theme 2: Good and open communication as formula to solve the challenge; Theme 3: Open-System of Communication lenses strategic mechanism; Theme 4: Collaboration Outshines Challenges and Demands.

The school heads as the highest authority on their respective schools are also vested with the biggest roles and responsibilities particularly in ensuring the school to offer quality education through quality instructions. As public servants, and just like other professions, the school heads also face numbers of challenges and demands on their position which mostly contributory to their roles as school leaders. The school heads as the leaders of the school need to possess the quality facing these challenges and to meet the demand of not just the school but also the community in the larger plane. They tend not just to simply 
comply with the requirements given by the higher offices but to dig deeper and to find ways on how to beat the challenges and the demands. The school heads also need to make their people realize the worth of their roles as principals that all of the activities undertaken are part of this role and also for the benefits of learners [5].

Despite of these enormous challenges and demands, school heads still uphold their position, motivated of performing their tasks, and still have the courage to face the challenges and the ever changing demands as forerunners of their respective schools [6]. The school heads deemed that the most powerful weapon that would make them surpass all these challenges and demands is their passions and dedication to their profession. No challenges and demands could ever beat the passionate and dedicated hearts of the school heads who passionately performed their roles and responsibilities whole-heartedly. They also believed that the school does not need astute and shrewd school heads, what the schools need are school heads who can duplicate themselves to ensure the quality of education and for the sake of the school as a whole. Others might have different views on how the principals perform their duties as school heads, but one thing for sure, all school principals' dream is to be part of the education system to cater quality instruction and to achieve the dream of the department of education to produce quality and competent graduates.

The school heads as the supervisors of instructions in their respective schools also believe that their goal to attain effective leadership and governance could not be achieved without the help of others. The school heads believe that even though it's a prime role of the school heads to execute leadership and management, but it could be executed better through collaboration with the teachers, the parents, and the stakeholders who are also concerned to quality of instruction. This also made the school heads to involve the internal and external stakeholders on their leadership and build them strong partnership for them to be able to bring the most appropriate and effective leadership and management of the school. They also believed that strong partnership with the internal and external stakeholders might also serve as a way to smoothly implement programs and projects necessary to obtain their ever support about it. It has also been expected that the teachers and the school principal shall work hand-in-hand for the success of the school. It is hard to determine what is most important since the work in schools, as in most organizations, is complex and intertwined.

As an output of this study, a compilation of inspirational testimonies of school principals has been created to inspire and motivate other principals, aspirant graduate school students to achieve what the participants have not intentionally achieved to be valuable and inspirational.

\section{Conclusions and Recommendation}

As to how the principals deal with the demands and challenges they encounter as school principal are as follows: Reading and scrutinizing the verbatim transcripts several times, and highlighting significant statements with their meanings most frequent demands and challenges encountered by the school principals.

The school principals as the head of their respective schools are much aware that they handle the biggest roles and responsibilities which are mostly related to their leadership and management of the school. The participants acknowledged that, despite of the pressure and tensions of serving as the heads of the school, the principals believed that the passion and dedication to their profession are still the most powerful tools to surpass the challenges and to deal with various demands. Their passion and dedication as school heads are the fountain source of strength in doing all their best to surpass the challenges and face the demands. The school heads need to be given sufficient trainings and workshops that would fully zero-in to their leadership and management of the school. Hence, an orientation that would further facilitate the understanding performance of the school heads in adherence to their duties and responsibilities. There is a need for the school heads to conduct sharing of the challenges and demands they face in order to acquire in-depth knowledge and explore better techniques in their respective schools. There is a need for this study to further offer an avenue to identify the challenges and demands which the school heads as the leaders of school would exceptionally experience.

\section{REFERENCES}

[1] Day, Jerome .(2016). School leadership that works: From research to results.

[2] Jomelogo, Ricardo .(2016). Teaching as Profession: Analysis of the Challenges encountered by Teachers. Eulogio “Amang Rodriguez Institute of Science and Technology.

[3] Creswell, J.W. (2014). Educational Research: Planning, conducting and evaluating quantitative and qualitative research (2nd ed.) Upper Saddle River, NJ: Pearson Education

[4] Husserl, E. (1977). Phenomenological psychology. (Trans. J. Scanlon). The Hague: Martinus Nijhoff Publishers. (German original, 1962)

[5] Dooble, M. J. (2017). "Ethics in School Administration" Educational Psychology. Ethics today and Tomorrow: A guiding Principle.

[6] Hilabus, H. J. (2018). Instructional leadership and the school principal: A passing fancy that refuses to fade away. Leadership and Policy in Schools, 4, 221-239 
[7] Elago, Norman .(2016). Instructional leadership and the school principal: A passing fancy that refuses to fade away. Leadership and Policy in Schools, 4, 221-239
[8] De Jesus, N. B. (2016). Creative Leadership and its Impact to the School as an Educational Institution. Unpublished Thesis. 